Review

\title{
Hydrogen Sulfide and Polysulfides as Biological Mediators
}

\section{Hideo Kimura}

National Institute of Neuroscience, National Center of Neurology and Psychiatry, Kodaira,

Tokyo 187-8502, Japan; E-Mail: kimura@ncnp.go.jp; Tel.: +81-42-346-1725; Fax: +81-42-346-1755

External Editor: Noriyuki Nagahara

Received: 16 September 2014; in revised form: 30 September 2014 / Accepted: 8 October 2014 / Published: 9 October 2014

\begin{abstract}
Hydrogen sulfide $\left(\mathrm{H}_{2} \mathrm{~S}\right)$ is recognized as a biological mediator with various roles such as neuromodulation, regulation of the vascular tone, cytoprotection, anti-inflammation, oxygen sensing, angiogenesis, and generation of mitochondrial energy. It is produced by cystathionine $\beta$-synthase (CBS), cystathionine $\gamma$-lyase (CSE), and 3-mercaptopyruvate sulfurtransferase (3MST). The activity of CBS is enhanced by $S$-adenosyl methionine (SAM) and glutathionylation, while it is inhibited by nitric oxide (NO) and carbon monoxide (CO). The activity of CSE and cysteine aminotransferase (CAT), which produces the $3 \mathrm{MST}$ substrate 3-mercaptopyruvate (3MP), is regulated by $\mathrm{Ca}^{2+} \cdot \mathrm{H}_{2} \mathrm{~S}$ is oxidized to thiosulfate in mitochondria through the sequential action of sulfide quinone oxidoreductase (SQR), sulfur dioxygenase, and rhodanese. The rates of the production and clearance of $\mathrm{H}_{2} \mathrm{~S}$ determine its cellular concentration. Polysulfides $\left(\mathrm{H}_{2} \mathrm{~S}_{\mathrm{n}}\right)$ have been found to occur in the brain and activate transient receptor potential ankyrin 1 (TRPA1) channels, facilitate the translocation of nuclear factor erythroid 2-related factor 2 ( Nrf2) to the nucleus, and suppress the activity of phosphatase and tensin homolog (PTEN) by sulfurating (sulfhydrating) the target cysteine residues. A cross talk between $\mathrm{H}_{2} \mathrm{~S}$ and $\mathrm{NO}$ also plays an important role in cardioprotection as well as regulation of the vascular tone. $\mathrm{H}_{2} \mathrm{~S}$, polysulfides, and their cross talk with NO may mediate various physiological and pathophysiological responses.
\end{abstract}

Keywords: $\mathrm{H}_{2} \mathrm{~S} ; \mathrm{H}_{2} \mathrm{~S}$; nitric oxide; CBS; CSE; 3MST; TRPA1; Nrf2; PTEN 


\section{Introduction}

Hydrogen sulfide $\left(\mathrm{H}_{2} \mathrm{~S}\right)$ readily dissolves in water, and dissociates to $\mathrm{H}^{+}, \mathrm{HS}^{-}$, and $\mathrm{S}^{2-}$. Under physiological conditions, approximately $20 \%$ exist as $\mathrm{H}_{2} \mathrm{~S}$ and the remaining $80 \%$ as $\mathrm{HS}^{-}$, with only trace amounts of $\mathrm{S}^{2-}$. The term "hydrogen sulfide" has been used to refer to $\mathrm{H}_{2} \mathrm{~S}, \mathrm{HS}^{-}$, and $\mathrm{S}^{2-}[1]$. $\mathrm{H}_{2} \mathrm{~S}$ was first detected in mammalian brains in 1989 [2-4]. The $\mathrm{H}_{2} \mathrm{~S}$ concentrations reported in these studies were later found to strongly overestimate the true concentrations [5-7]. This discrepancy has been explained by the use of inappropriate methods to measure free $\mathrm{H}_{2} \mathrm{~S}$ in the original studies. Nevertheless, the fact that the refined methods used in recent studies detected $\mathrm{H}_{2} \mathrm{~S}$, albeit at low concentrations, confirmed the existence of $\mathrm{H}_{2} \mathrm{~S}$ in cells. A possible role for $\mathrm{H}_{2} \mathrm{~S}$ as a neuromodulator in the brain, and its generation by cystathionine $\beta$-synthase (CBS), was demonstrated [1]. Subsequently, an additional function as a smooth muscle relaxant was reported for $\mathrm{H}_{2} \mathrm{~S}$, together with evidence that suggests it is also produced by cystathionine $\gamma$-lyase (CSE) [8,9]. Based on the observation that $\mathrm{H}_{2} \mathrm{~S}$ is produced in the brains of CBS-knockout mice, 3-mercaptopyruvate sulfurtransferase (3MST) together with cysteine aminotransferase (CAT), which is identical to aspartate sulfurtransferase (AAT), was shown to produce $\mathrm{H}_{2} \mathrm{~S}$ in the presence of thioredoxin [10-12]. Recently, we found a novel pathway consisting of 3MST and D-amino-acid oxidase (DAO) that generates $\mathrm{H}_{2} \mathrm{~S}$ from D-cysteine [13].

Although the relaxation effect of $\mathrm{H}_{2} \mathrm{~S}$ alone on the thoracic aorta was much weaker than that on the portal vein and ileum, $\mathrm{H}_{2} \mathrm{~S}$ efficiently relaxes vascular smooth muscle in synergy with nitric oxide (NO) [8]. The chemical interaction of $\mathrm{H}_{2} \mathrm{~S}$ and NO produces nitrosothiol, which releases $\mathrm{NO}$ in the presence of $\mathrm{Cu}^{2+}$ [14]. Nitrosoglutathione (GSNO), which also functions as a carrier of NO, releases $\mathrm{NO}$ in the presence of $\mathrm{H}_{2} \mathrm{~S}$ to induce vascular smooth muscle relaxation [15]. Recently, it was demonstrated that $\mathrm{H}_{2} \mathrm{~S}$ and nitrite interact with each other and produce HSNO and HNO [16]. A further reaction with $\mathrm{H}_{2} \mathrm{~S}$ has been proposed to generate HSSNO, which releases NO and polysulfides to activate soluble guanylyl cyclase and relax vascular smooth muscle [17].

$\mathrm{H}_{2} \mathrm{~S}$ also regulates the activity of $\mathrm{NO}$ synthetase (NOS) to control the production of $\mathrm{NO} \mathrm{H}_{2} \mathrm{~S}$ facilitates the phosphorylation of the endothelial NOS (eNOS) activation site to increase NO production, whereas it does not induce the phosphorylation of its inhibitory site [18]. Through these effects, $\mathrm{H}_{2} \mathrm{~S}$ protects cardiac muscle from ischemia/reperfusion injury. The mechanism is supported by the observations that $\mathrm{NO}$ availability is low in CSE-knockout mice, but can be rescued by $\mathrm{H}_{2} \mathrm{~S}$ administration. In contrast, the activity of neuronal NOS (nNOS) is suppressed by $\mathrm{H}_{2} \mathrm{~S}$ in colon smooth muscle [19]. In this tissue, endogenously produced NO is significantly greater in CSE-knockout mice than in the wild type.

The significance of polysulfides in $\mathrm{H}_{2} \mathrm{~S}$ biology has recently been recognized; their role in the sulfuration (sulfhydration) of cysteine residues in target proteins to modify their activities has been documented [20,21]. Polysulfides were found to occur in the brain and to activate transient receptor potential ankyrin 1 (TRPA1) channels by sulfurating cysteine residues localized at the amino-terminus of the channels [22-25]. The regulation of phosphatase and tensin homolog (PTEN) activity by polysulfides was subsequently shown [26]. The transcription factor nuclear factor erythroid 2-related factor 2 (Nrf2) is normally sequestered in the cytosol by two molecules of Kelch-like ECH-associated protein 1 (Keap1). Once a reactive cysteine residue in Keap1 is sulfurated by polysulfides, Nrf2 is released by Keap1, after which it translocates to the nucleus, and upregulates the transcription of 
antioxidant genes [27]. Glutathione persulfide (GSSH) inhibits cytochrome $c$ and scavenges hydrogen peroxide $\left(\mathrm{H}_{2} \mathrm{O}_{2}\right)$ more efficiently than glutathione [28-30]. GSSH can be produced by the metabolism of $\mathrm{H}_{2} \mathrm{~S}$ by sulfide quinone oxidoreductase (SQR) in mitochondria [31-33]. It may also be produced from cysteine persulfide (CysSSH), which has been proposed to be produced by CBS and CSE with cystine as a substrate, though the physiological relevance of the pathway has to be re-evaluated [30]. Polysulfides contain sulfane sulfur, which exists in a higher oxidation state than the sulfur atom in $\mathrm{H}_{2} \mathrm{~S}$ and exerts various physiological effects.

\section{The Regulation of Local $\mathrm{H}_{2} \mathrm{~S}$ Concentrations}

The concentration of $\mathrm{H}_{2} \mathrm{~S}$ is determined by the balance between its production and clearance. $\mathrm{H}_{2} \mathrm{~S}$ is produced by CBS, CSE, and $3 \mathrm{MST}$ and is metabolized by $\mathrm{H}_{2} \mathrm{~S}$ oxidation pathways (Figure 1).

Figure 1. The metabolic turnover of $\mathrm{H}_{2} \mathrm{~S} . \mathrm{H}_{2} \mathrm{~S}$ is produced by cystathionine $\beta$-synthase (CBS), cystathionine $\gamma$-lyase (CSE), and 3-mercaptopyruvate sulfurtransferase (3MST), and oxidized by sulfide quinone oxidoreductase (SQR) in mitochondria to produce persulfide. Sulfur dioxygenase oxidizes persulfide to sulfite $\left(\mathrm{H}_{2} \mathrm{SO}_{3}\right)$, which is metabolized by rhodanese to produce thiosulfate $\left(\mathrm{H}_{2} \mathrm{~S}_{2} \mathrm{O}_{3}\right)$. The balance between $\mathrm{H}_{2} \mathrm{~S}$ production and clearance of $\mathrm{H}_{2} \mathrm{~S}$ determines its cellular concentration.

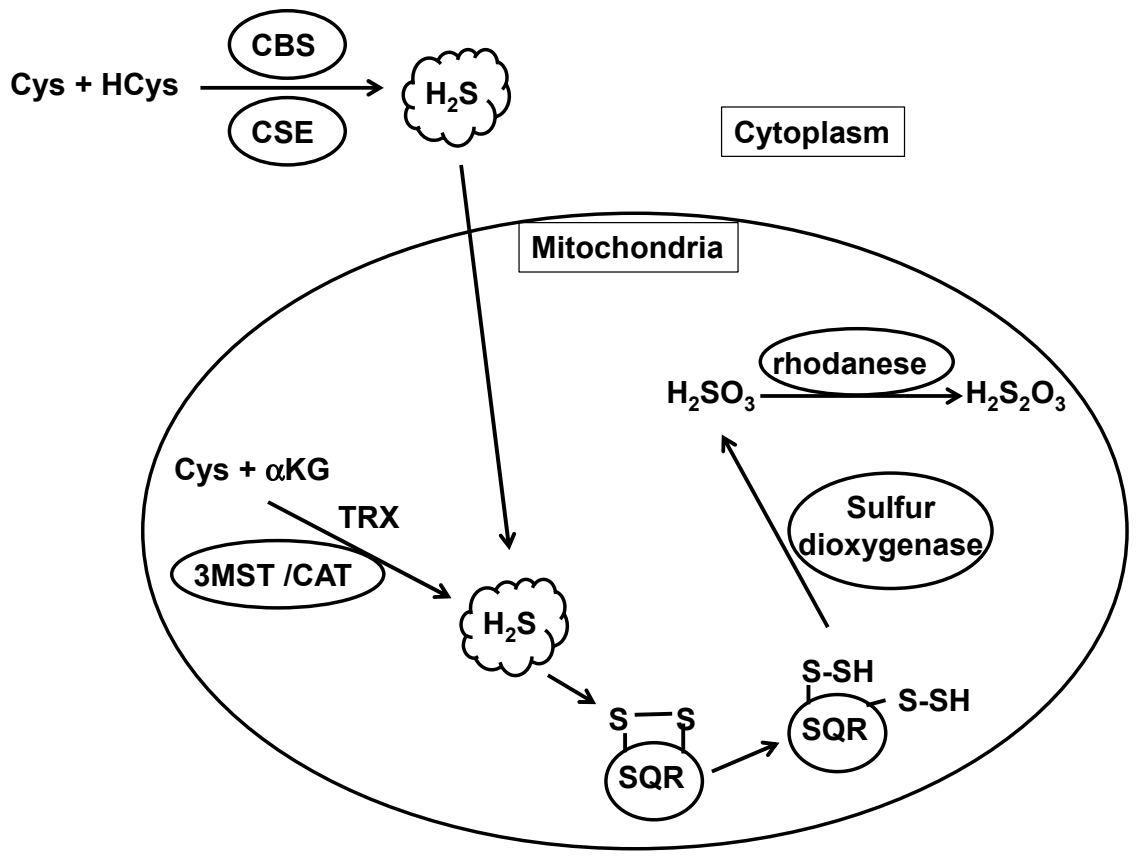

$\mathrm{H}_{2} \mathrm{~S}$ production by CBS is enhanced by $S$-adenosyl methionine (SAM), which binds to the SAM binding site located at the carboxy-terminus [1,34]. The activity of CBS is also enhanced by glutathionylation of Cys346 [35]. Under oxidative stress, glutathione is consumed to protect cells, and Cys346 of CBS is oxidized to a sulfenic acid that then reacts with glutathione. Glutathionylated CBS increases the production of cysteine and $\mathrm{H}_{2} \mathrm{~S}$, which in turn promotes the production of glutathione. In contrast to the regulation by SAM and glutathionylation, the binding of NO and carbon monoxide (CO) to a heme group at the amino-terminus suppresses the activity of CBS [36]. This negative regulation plays an important role in the hypoxic brain [37], when the production of $\mathrm{CO}$ by heme 
oxygenase is decreased. The reduction of $\mathrm{CO}$ levels causes the de-suppression of CBS activity in astrocytes, which surround capillaries. CBS-derived $\mathrm{H}_{2} \mathrm{~S}$ then relaxes the capillaries to recover blood flow and oxygen supply.

CSE was previously reported to be regulated by $\mathrm{Ca}^{2+} /$ calmodulin [38]. However, this study was performed in the presence of $1-2 \mathrm{mM} \mathrm{Ca}^{2+}$, which corresponds to the extracellular $\mathrm{Ca}^{2+}$ concentration. Because CSE is a cytosolic enzyme, an investigation of the influence of intracellular $\mathrm{Ca}^{2+}$ concentrations on CSE activity was required. At steady state, the intracellular concentration of $\mathrm{Ca}^{2+}$ is approximately $100 \mathrm{nM}$; it is increased up to approximately $3 \mu \mathrm{M}$ when cells are stimulated. In the presence of steady-state intracellular $\mathrm{Ca}^{2+}$ concentrations, CSE was found to be active, whereas it is inhibited by $50 \%$ in the presence of more than $300 \mathrm{nM} \mathrm{Ca}^{2+}$. It should be noted that CSE activity is suppressed by $\mathrm{Ca}^{2+}$ without the involvement of calmodulin [39].

The production of $\mathrm{H}_{2} \mathrm{~S}$ via the $3 \mathrm{MST} / \mathrm{CAT}$ pathway is also regulated by $\mathrm{Ca}^{2+}$ [40]. The activity of CAT is maximal at steady-state $\mathrm{Ca}^{2+}$ concentrations, whereas it is suppressed by $\mathrm{Ca}^{2+}$ in a concentration-dependent manner and is almost abolished when $\mathrm{Ca}^{2+}$ concentrations reach $3 \mu \mathrm{M}$. Calmodulin is not involved in the regulation of CAT. Because 3MST requires thioredoxin to produce $\mathrm{H}_{2} \mathrm{~S}$, the availability of thioredoxin and its redox turnover affect the $\mathrm{H}_{2} \mathrm{~S}$-producing activity of $3 \operatorname{MST}[11,12,41]$.

In contrast to the regulation of $\mathrm{H}_{2} \mathrm{~S}$-producing enzymes, that of $\mathrm{H}_{2} \mathrm{~S}$-metabolizing enzymes such as sulfide quinone oxidoreductase, persulfide dioxygenase, and rhodanese, is poorly understood.

$\mathrm{H}_{2} \mathrm{~S}$ can also be released from bound sulfane sulfur. The time-course of this process as well as the amount of $\mathrm{H}_{2} \mathrm{~S}$ released vary among tissues [6]. Homogenates of neurons and astrocytes release $\mathrm{H}_{2} \mathrm{~S}$ in the presence of endogenous concentrations of cysteine and glutathione. However, the release of $\mathrm{H}_{2} \mathrm{~S}$ from intact astrocytes, during neuronal excitation, has not yet been successfully detected.

\section{Polysulfides as Biological Mediators}

\subsection{Effects of Polysulfides}

Neurons are surrounded by astrocytes, which are glial cells that display neurotransmitter receptors. Presynaptic neurons release a neurotransmitter to postsynaptic neurons; some of them activate surrounding astrocytes, which in turn release gliotransmitters to modify synaptic activity. $\mathrm{H}_{2} \mathrm{~S}$ induces $\mathrm{Ca}^{2+}$-influx in astrocytes by activating transient receptor potential (TRP) channels [42,43]. We subsequently found that polysulfide salts, i.e., sodium tri- and tetrasulfide $\left(\mathrm{Na}_{2} \mathrm{~S}_{3}\right.$ and $\left.\mathrm{Na}_{2} \mathrm{~S}_{4}\right)$, activate TRP channels in astrocytes much more potently than $\mathrm{H}_{2} \mathrm{~S}$, although the subtype of TRP channels was not identified [22]. TRPA1 channels were found to be activated by high concentrations of sodium hydrosulfide (NaHS) (1-10 mM) in sensory neurons of the urinary bladder and dorsal ganglion cells $[24,44] . \mathrm{H}_{2} \mathrm{~S}$ is readily oxidized to polysulfides, and is sequentially oxidized to polysulfides with a varying number of sulfur atoms, until the number of sulfur atoms reaches eight; at that point, the sulfur molecules cyclize and separate from polysulfides $\left(\mathrm{H}_{2} \mathrm{~S}_{n}\right.$; see Equations (1) and (2)).

$$
\begin{aligned}
& 2 \mathrm{nH}_{2} \mathrm{~S}+1 / 2(2 \mathrm{n}-1) \mathrm{O}_{2}=\mathrm{H}_{2} \mathrm{~S}_{2 \mathrm{n}}+(2 \mathrm{n}-1) \mathrm{H}_{2} \mathrm{O} \\
& \mathrm{HS}^{-} \leftrightarrow \mathrm{HSS}^{-} \leftrightarrow \mathrm{HSSS}^{-} \leftrightarrow \ldots . . \leftrightarrow \mathrm{HS}_{7}^{-} \rightarrow \mathrm{S}_{8}
\end{aligned}
$$


It is possible that some of the $\mathrm{H}_{2} \mathrm{~S}$ used in these studies was oxidized to $\mathrm{H}_{2} \mathrm{~S}_{\mathrm{n}}$, which in turn activated TRPA1 channels [21,23,45].

Using selective agonists and antagonists as well as siRNA targeting TRPA1 revealed that $\mathrm{H}_{2} \mathrm{~S}_{\mathrm{n}}$ activate TRPA1 channels in astrocytes much more potently than $\mathrm{H}_{2} \mathrm{~S}$ [25]. The $\mathrm{K}_{\mathrm{m}}$ value for the activation of TRPA1 channels in astrocytes is approximately $90 \mathrm{nM}$, and an HPLC analysis in the same study found approximately $20 \mu \mathrm{M}$ polysulfides in the brain.

\subsection{A Mechanism for Polysulfide Activity}

Sulfuration modifies enzyme activity, which has been extensively studied between the 1960s and 1980s [46-48]. The process, in which $\mathrm{H}_{2} \mathrm{~S}$-derived sulfur attaches to reactive cysteine residues of target proteins, was named sulfhydration by Snyder and colleagues, while Toohey later suggested that the correct term is sulfuration [20,21]. Sulfuration of glyceraldehyde-3-phosphate dehydrogenase $(\mathrm{GAPDH})$ by $\mathrm{H}_{2} \mathrm{~S}$ increases its catalytic activity, and that of actin facilitates its polymerization. Consistently, dithiothreitol (DTT) treatment removes the added sulfur and diminishes the activity of these proteins [20]. ATP-dependent $\mathrm{K}^{+}$channels are activated by sulfuration, and sulfuration of nuclear factor $\kappa \mathrm{B}(\mathrm{NF}-\kappa \mathrm{B})$ facilitates its translocation to the nucleus. In contrast, protein tyrosine phosphatase 1B (PTP1B) is inhibited by sulfuration, thus regulating the endoplasmic reticulum stress response [49-51]. Parkin is an E3 ubiquitin ligase that is affected in Parkinson's disease and causes accumulation of $\alpha$-synuclein, a major component of Lewy bodies; Parkin is activated by sulfuration at Cys95 and Cys59 [52].

$\mathrm{Zhu}$ and colleagues proposed a role for $\mathrm{H}_{2} \mathrm{~S}$ in the reduction of cysteine disulfide bonds rather than in the sulfuration of cysteine residues. $\mathrm{H}_{2} \mathrm{~S}$ activates vascular endothelial growth factor receptor 2 (VEGFR2), which induces angiogenesis by reducing a disulfide bond between Cys1045 and Cys1024 [53]. Mass spectrometric analysis shows that $\mathrm{H}_{2} \mathrm{~S}$ reduces the cysteine disulfide bond existing in the synthesized hexapeptide, but does not sulfurate any of the 20 free amino acids, including cysteine. The sulfuration of cysteine residues is only transiently observed as an intermediate during the $\mathrm{H}_{2} \mathrm{~S}$-mediated reduction of the disulfide bond, and the intermediate is immediately reduced to cysteine through an attack by a second $\mathrm{HS}^{-}$molecule.

Atoms in the same oxidation state do not exchange electrons that results in no redox reaction. Because the oxidation state of sulfur in $\mathrm{H}_{2} \mathrm{~S}$ and in free cysteine residues is -2 , they do not react with each other. Ogawa et al. reported that the sites of TRPA1 channels sensitive to high concentrations of $\mathrm{H}_{2} \mathrm{~S}$ are Cys422 and Cys622 at the amino-terminus, and that DTT abolishes the effect of $\mathrm{H}_{2} \mathrm{~S}$ [24]. These observations suggest that Cys422 and Cys622 are sulfurated or bridged by a disulfide bond. $\mathrm{H}_{2} \mathrm{~S}_{3}$ and $\mathrm{H}_{2} \mathrm{~S}_{4}$ activate TRPA1 much more potently than $\mathrm{H}_{2} \mathrm{~S}$ [25]. Because the oxidation state of sulfur in polysulfides such as $\mathrm{H}_{2} \mathrm{~S}_{3}$ and $\mathrm{H}_{2} \mathrm{~S}_{4}$ is 0 , polysulfides can readily gain electrons from sulfur (-2) in cysteine residues. Therefore, both cysteine residues in TRPA1 are more likely to be sulfurated by polysulfides produced by $\mathrm{H}_{2} \mathrm{~S}$ oxidation than by $\mathrm{H}_{2} \mathrm{~S}$ per se. However, both cysteine residues may not be sulfurated simultaneously; in that case, the sulfurated cysteine residue may be attacked by the second free cysteine residue to produce the cysteine disulfide bond between Cys 422 and Cys622 (Figure 2). 
Figure 2. Polysulfides sulfurate cysteine residues of TRPA1 channels to modify their activity. Polysulfides sulfurate Cys422 and Cys622 at the amino-terminus of transient receptor potential ankyrin 1 (TRPA1) channels to activate them.

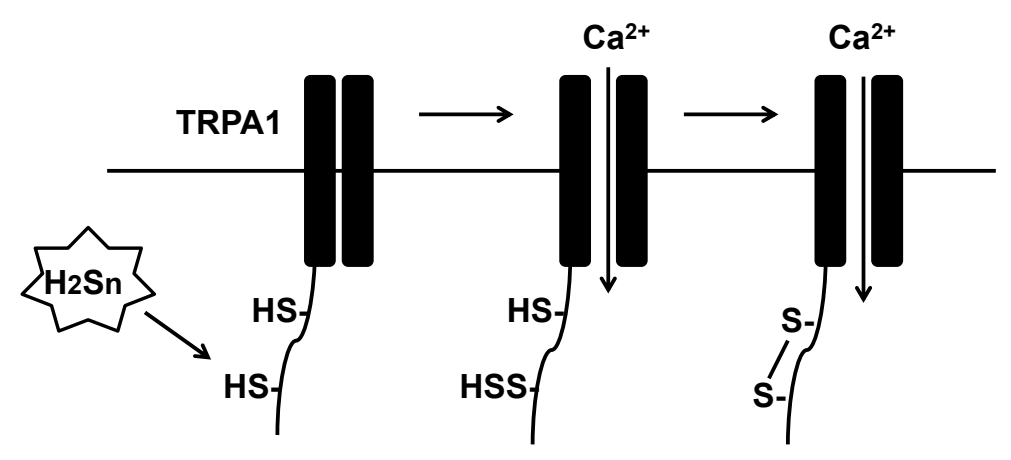

There are other examples for polysulfide-mediated sulfuration that were previously ascribed to $\mathrm{H}_{2} \mathrm{~S}$. Lefer and colleagues initially reported that $\mathrm{H}_{2} \mathrm{~S}$ facilitates the translocation of $\mathrm{Nrf2}$ to the nucleus to upregulate the transcription of antioxidant genes [54]. Wang and colleagues showed that $\mathrm{H}_{2} \mathrm{~S}$ sulfurates Keap1 to release Nrf2 to the nucleus [55]. We showed that polysulfides sulfurate Keap1 (Figure 3) [27]. Polysulfides, but not $\mathrm{H}_{2} \mathrm{~S}$, inhibit the activity of lipid phosphatase and tensin homolog (PTEN) by inducing the formation of a cysteine disulfide bond [26]. In the latter study, mass spectrometric analysis revealed only the cysteine disulfide bond, but not the trisulfide bond suggested by Toohey [21].

Figure 3. Sulfration of Keap1 by polysulfides release Nrf2 to the nucleus. Nuclear factor erythroid 2-related factor 2 (Nrf2) is sequestered in the cytosol by two molecules of Kelch-like ECH-associated protein 1 (Keap1). When Keap1 is sulfurated by polysulfides, $\mathrm{Nrf} 2$ is released and translocates into the nucleus, where it upregulates the transcription of antioxidant genes.

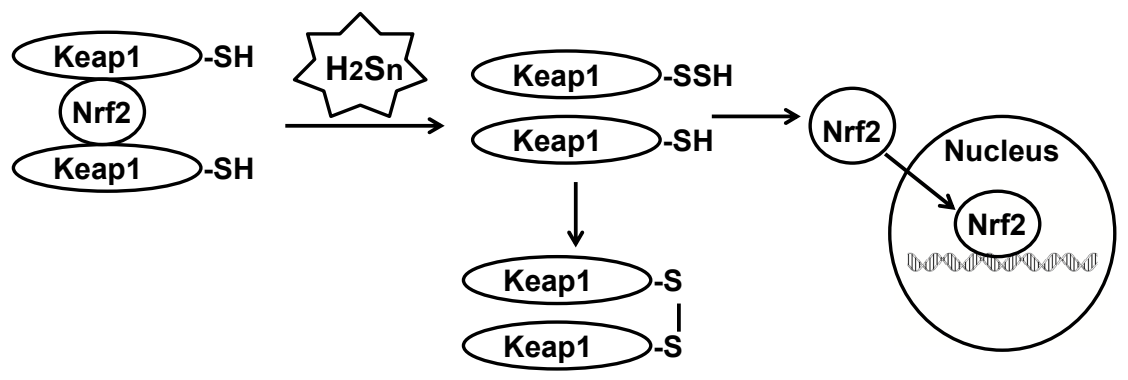

\subsection{Glutathione Polysulfide}

Massey et al. initially reported that glutathione persulfide (GSSH or $\mathrm{GSS}^{-}$) produced from glutathione trisulfide (GSSSG) reduces cytochrome $c$ more efficiently than glutathione (GSH), and that cysteine trisulfide has a similar effect [28]. The effect of GSSH on cytochrome $c$ was confirmed, and a similar reductive effect was observed on papain [29]. GSSH produced from GSSSG scavenges $\mathrm{H}_{2} \mathrm{O}_{2}$ more efficiently than GSH [30].

GSH receives a sulfur atom from $\mathrm{H}_{2} \mathrm{~S}$ through the action of $\mathrm{SQR}$ to form GSSH in mitochondria [31-33]. An alternative pathway to produce cysteine persulfide (CysSSH) and GSSH has 
been proposed [30]. CBS and CSE metabolize cystine to CysSSH, which produces GSSH via the exchange reaction with GSH. However, the physiological relevance of this pathway needs to be re-evaluated. CSE has a high affinity for cystine, the extracellular form of cysteine, with a $\mathrm{K}_{\mathrm{m}}$ value of 30-70 $\mu \mathrm{M}$. However, CBS and CSE localize to the cytosol, which contains concentrations of cystine that are insufficient to allow the enzymatic reaction [56]. Less than $0.2 \mu \mathrm{M}$ cystine exists in the cytosol, with a few exceptions such as the A549 cell line, which contains approximately $12 \mu \mathrm{M}$ cystine in the cytosol [30]. Even the extracellular concentration of cystine is only approximately $40 \mu \mathrm{M}$ in human blood [57]. The in vitro generation of CysSSH by CSE and CBS was examined in the presence of millimolar concentrations of cystine, which greatly exceed physiological concentrations [30].

\section{Cross Talk of $\mathrm{H}_{2} \mathrm{~S}$ and NO}

$\mathrm{H}_{2} \mathrm{~S}$ relaxes vascular smooth muscle in synergy with $\mathrm{NO}$, and a similar synergistic effect is observed in ileum $[8,58]$. NO also enhances the production of $\mathrm{H}_{2} \mathrm{~S}$ and upregulates the transcription of CSE [9]. Lefer and colleagues recently showed that $\mathrm{H}_{2} \mathrm{~S}$ activates eNOS by inducing the phosphorylation of its activation site; the subsequent increase in the production of NO protects the heart from ischemia/reperfusion injury [18]). This mechanism was confirmed by the observation that the administration of $\mathrm{H}_{2} \mathrm{~S}$ did not confer cardioprotection in eNOS-deficient mice. In contrast, nNOS is inhibited by $\mathrm{H}_{2} \mathrm{~S}$ in colon smooth muscle [19], as indicated by the observation that the endogenous generation of NO is significantly decreased in wild-type mice compared with CSE-knockout mice.

The chemical interaction between $\mathrm{H}_{2} \mathrm{~S}$ and $\mathrm{NO}$ produces several potential intermediates. Nitrosothiol releases $\mathrm{NO}$ in the presence of $\mathrm{Cu}^{2+}$. GSNO, which is an intermediate or a carrier of NO, releases $\mathrm{NO}$ in the presence of $\mathrm{H}_{2} \mathrm{~S}[14,15] . \mathrm{H}_{2} \mathrm{~S}$ and nitrite, in the presence of human umbilical vein endothelial cells or $\mathrm{Fe}^{3+}$-porphyrins, produce the intermediate $\mathrm{HSNO}$, which in turn generates either $\mathrm{NO}$ and the HS radical, or HNO by a further reaction with $\mathrm{H}_{2} \mathrm{~S}$ [16]. Feelisch and colleagues reported that HSNO may not effectively release NO because the S-N bond is too strong. They demonstrated that nitrosopersulfide $\left(\mathrm{SSNO}^{-}\right)$, which is more stable than $\mathrm{HSNO}$, efficiently releases $\mathrm{NO}$ and polysulfides to activate soluble guanylyl cyclase and relax smooth muscle [17]. These studies on the chemical interaction of $\mathrm{H}_{2} \mathrm{~S}$ and $\mathrm{NO}$ were performed in the presence of millimolar concentrations of NaHS, which is why their physiological relevance needs to be further examined.

\section{Conclusions}

The role of $\mathrm{H}_{2} \mathrm{~S}$ as a physiological mediator has been extensively studied in various tissues and organs. Although the steady-state concentrations of $\mathrm{H}_{2} \mathrm{~S}$ have been re-evaluated and found to be much lower than those initially reported, neither the range of concentration changes nor the physiological stimuli to induce such changes have been understood. The balance between the production and clearance of $\mathrm{H}_{2} \mathrm{~S}$ determines its concentration [59,60]. $S$-adenosyl methionine and glutathionylation enhance the activity of CBS, whereas NO and CO suppress it. CSE and CAT are regulated by $\mathrm{Ca}^{2+}$. In contrast, the regulation of $\mathrm{H}_{2} \mathrm{~S}$-degrading enzymes such as $\mathrm{SQR}$ and sulfur dioxygenase is only poorly understood.

Polysulfides have recently been recognized as potential physiological mediators. They have been found to occur in tissues and to activate channels, enzymes, and transcription factors through the mechanism of sulfuration (sulfhydration). However, a number of issues remain to be clarified, such as 
the production and degradation pathways of polysulfides and their regulatory mechanisms, as well as potential physiological stimuli that induce those regulatory mechanisms.

The cross talk between $\mathrm{H}_{2} \mathrm{~S}$ and $\mathrm{NO}$ has also been extensively studied. A synergistic effect of $\mathrm{H}_{2} \mathrm{~S}$ and $\mathrm{NO}$ was initially found. Recently, it was demonstrated that $\mathrm{H}_{2} \mathrm{~S}$ acts as a stimulator of the release of $\mathrm{NO}$, which is the final effecter molecule to the target proteins. In addition, the reaction of $\mathrm{H}_{2} \mathrm{~S}$ with NO, which gives rise to highly reactive substances, such as HSNO, GSNO, HNO, and HSSNO has been proposed. The production of the latter substances will have to be re-evaluated under physiological conditions.

A better understanding of the regulation of their production as well as their mechanisms of action will help unveil the physiological roles of $\mathrm{H}_{2} \mathrm{~S}$ and related molecules.

\section{Acknowledgments}

This work was supported by a grant from the National Institute of Neuroscience, and a KAKENHI (23659089) Grant-in-Aid for Challenging Exploratory Research and KAKENHI (26460115) Grant-in-Aid for Scientific Research to H.K.

\section{Conflicts of Interest}

There is not conflict of interest.

\section{References}

1. Abe, K.; Kimura, H. The possible role of hydrogen sulfide as an endogenous neuromodulator. J. Neurosci. 1996, 16, 1066-1071.

2. Goodwin, L.R.; Francom, D.; Dieken, F.P.; Taylor, J.D.; Warenycia, M.W.; Reiffenstein, R.J.; Dowling, G. Determination of sulfide in brain tissue by gas dialysis/ion chromatography: Postmortem studies and two case reports. J. Anal. Toxicol. 1989, 13, 105-109.

3. Warenycia, M.W.; Goodwin, L.R.; Benishin, C.G.; Reiffenstein, R.J.; Grancom, D.M.; Taylor, J.D.; Dieken, F.P. Acute hydrogen sulfide poisoning. Demonstration of selective uptake of sulfide by the brainstem by measurement of brain sulfide levels. Biochem. Pharmacol. 1989, 38, 973-981.

4. Savage, J.C.; Gould, D.H. Determination of sulfide in brain tissue and rumen fluid by ion-interaction reversed-phase high-performance liquid chromatography. J. Chromatogr. B 1990, 526, 540-545.

5. Furne, J.; Saeed, A.; Levitt, M.D. Whole tissue hydrogen sulfide concentrations are orders of magnitude lower than presently accepted values. Am. J. Physiol. Regul. Integr. Comp. Physiol. 2008, 295, R1479-R1498.

6. Ishigami, M.; Hiraki, K.; Umemura, K.; Ogasawara, Y.; Ishii, K.; Kimura, H. A source of hydrogen sulfide and a mechanism of its release in the brain. Antioxid. Redox Signal. 2009, 11, 205-214.

7. Wintner, E.A.; Deckwerth, T.L.; Langston, W.; Bengtsson, A.; Leviten, D.; Hill, P.; Insko, M.A.; Dumpit, R.; VandenEkart, E.; Toombs, C.F.; et al. A monobromobimane-based assay to measure the pharmacokinetic profile of reactive sulphide species in blood. Br. J. Pharmacol. 2010, 160, 941-957. 
8. Hosoki, R.; Matsuki, N.; Kimura, H. The possible role of hydrogen sulfide as an endogenous smooth muscle relaxant in synergy with nitric oxide. Biochem. Biophys. Res. Commun. 1997, 237, $527-531$.

9. Zhao, W.; Zhang, J.; Lu, Y.; Wang, R. The vasorelaxant effect of $\mathrm{H}_{2} \mathrm{~S}$ as a novel endogenous gaseous KATP channel opener. EMBO J. 2001, 20, 6008-6016.

10. Shibuya, N.; Tanaka, M.; Yoshida, M.; Ogasawara, Y.; Togawa, T.; Ishii, K.; Kimura, H. 3-Mercaptopyruvate sulfurtransferease produces hydrogen sulfide and bound sulfane sulfur in the brain. Antioxid. Redox Signal. 2009, 11, 703-714.

11. Mikami, Y.; Shibuya, N.; Kimura, Y.; Nagahara, N.; Ogasawara, Y.; Kimura, H. Thioredoxin and dihydrolipoic acid are required for 3-mercaptopyruvate sulfurtransferase to produce hydrogen sulfide. Biochem. J. 2011, 439, 479-485.

12. Yadav, P.K.; Yamada, K.; Chiku, T.; Koutmos, M.; Banerjee, R. Structure and kinetic analysis of $\mathrm{H}_{2} \mathrm{~S}$ production by human mercaptopyruvate sulfurtransferase. J. Biol. Chem. 2013, 288, 20002-20013.

13. Shibuya, N.; Koike, S.; Tanaka, M.; Ishigami-Yuasa, M.; Kimura, Y.; Ogasawara, Y.; Fukui, K.; Nagahara, N.; Kimura, H. A novel pathway for the production of hydrogen sulfide from D-cysteine in mammalian cells. Nat. Commun. 2013, 4, doi:10.1038/ncomms2371.

14. Whiteman, M.; Li, L.; Kostetski, I.; Chu, S.H.; Siau, J.L.; Bhatia, M.; Moore, P.K. Evidence for the formation of a novel nitrosothiol from the gaseous mediators nitric oxide and hydrogen sulphide. Biochem. Biophys. Res. Commun. 2006, 343, 303-310.

15. Ondrias, K.; Stasko, A.; Cacanyiova, S.; Sulova, Z.; Krizanova, O.; Kristek, F.; Malekova, L.; Knezl, V.; Breier, A. $\mathrm{H}_{2} \mathrm{~S}$ and HS- donor NaHS releases nitric oxide from nitrosothiols, metal nitrosyl complex, brain homogenate and murine L1210 leukaemia cells. Pflug. Arch. Eur. J. Physiol. 2008, 457, 271-279.

16. Filipovic, M.R.; Miljkovic, J.L.; Nauser, T.; Royzen, M.; Klos, K.; Shubina, T.; Koppenol, W.H.; Lippard, S.J.; Ivanovic-Burmazovic, I. Chemical characterization of the smallest $S$-nitrosothiol, HSNO; cellular cross-talk of $\mathrm{H}_{2} \mathrm{~S}$ and S-nitrosothiols. J. Am. Chem. Soc. 2012, 134, 12016-12027.

17. Cortese-Krott, M.M.; Fernandez, B.O.; Santos, J.L.T.; Mergia, E.; Grman, M.; Nagy, P.; Kelm, M.; Butler, A.; Feelisch, M. Nitrosopersulfide $\left(\mathrm{SSNO}^{-}\right)$accounts for sustained NO bioactivity of $S$-nitrosothiols following reaction with sulfide. Redox Biol. 2014, 2, 234-244.

18. King, A.L.; Polhemus, D.; Bhushan, S.; Otsuka, H.; Kondo, K.; Nicholson, C.K.; Bradley, J.M.; Islam, K.N.; Calvert, J.W.; Tao, Y.-X.; et al. Hydrogen sulfide cytoprotective signaling is endothelial nitric oxide synthase-nitric oxide dependent. Proc. Natl. Acad. Sci. USA 2014, 111, 3182-3187.

19. Sha, L.; Linden, D.R.; Farrugia, G.; Szurszewski, J.H. Effect of endogenous hydrogen sulfide on the transwall gradient of the mouse colon circular smooth muscle. J. Physiol. 2014, 592, 1077-1089.

20. Mustafa, A.K.; Gadalla, M.M.; Sen, N.; Kim, S.; Mu, W.; Gazi, S.K.; Barrow, R.K.; Yang, G.; Wang, R.; Snyder, S.H. H2S signals through protein S-sulfhydration. Sci. Signal. 2009, 2, ra72.

21. Toohey, J.I. Sulfur signaling: Is the agent sulfide or sulfane? Anal. Biochem. 2011, 413, 1-7.

22. Nagai, Y.; Tsugane, M.; Oka, J.-I.; Kimura, H. Polysulfides induce calcium waves in rat hippocampal astrocytes. J. Pharmacol. Sci. 2006, 100, 200.

23. Oosumi, K.; Tsugane, M.; Ishigami, M.; Nagai, Y.; Iwai, T.; Oka, J.; Kimura, H. Polysulfide activates TRP channels and increases intracellular $\mathrm{Ca}^{2+}$ in astrocytes. Neurosci. Res. 2010, 685, e109-e222. 
24. Ogawa, H.; Takahashi, K.; Miura, S.; Imagawa, T.; Saito, S.; Tominaga, M.; Ohta, T. H2S functions as a nociceptive messenger throughtransient receptor potential ankyrin 1 (TRPA1) activation. Neuroscience 2012, 218, 335-343.

25. Kimura, Y.; Mikami, Y.; Osumi, K.; Tsugane, M.; Oka, J.-I.; Kimura, H. Polysulfides are possible $\mathrm{H}_{2} \mathrm{~S}$-derived signaling molecules in rat brain. FASEB J. 2013, 27, 2451-2457.

26. Greiner, R.; Palinkas, Z.; Basell, K.; Becher, D.; Antelmann, H.; Nagy, P.; Dick, T.P. Polysulfides link $\mathrm{H}_{2} \mathrm{~S}$ to protein thiol oxidation. Antioxid. Redox Signal. 2013, 19, 1749-1765.

27. Koike, S.; Ogasawara, Y.; Shibuya, N.; Kimura, H.; Ishii, K. Polysulfide exerts a protective effect against cytotoxicity cuased by $t$-buthylhydroperoxide through $\mathrm{Nrf} 2$ signaling in neuroblastoma cells. FEBS Lett. 2013, 587, 3548-3555.

28. Massey, V.; Williams, C.H.; Palmer, G. The presence of S0-containing impurities in commercial samples of oxidized glutathione and their catalytic effect in the reduction of cytochrome c. Biochem. Biophys. Res. Commun. 1971, 42, 730-738.

29. Francoleon, N.E.; Carrington, S.J.; Fukuto, J.M. The reaction of $\mathrm{H}_{2} \mathrm{~S}$ with oxidized thiols: Generation of persulfides and implications to $\mathrm{H}_{2} \mathrm{~S}$ biology. Arch. Biochem. Biophys. 2011, 516, 146-153.

30. Ida, T.; Sawa, T.; Ihara, H.; Tsuchiya, Y.; Watanabe, Y.; Kumagai, Y.; Suematsu, M.; Motohashi, H.; Fujii, S.; Matsunaga, T.; et al. Reactive cysteine persulfides and $S$-polythiolation regulate oxidative stress and redox signaling. Proc. Natl. Acad. Sci. USA 2014, 111, 7606-7611.

31. Hildebrandt, T.M.; Grieshaber, M.K. Three enzymatic activities catalyze the oxidation of sulfide to thiosulfate in mammalian and invertebrate mitochondria. FEBS J. 2008, 275, 3352-3361.

32. Tiranti, V.; Viscomi, C.; Hildebrandt, T.; Meo, I.D.; Mineri, R.; Tiveron, C.; Levitt, M.D.; Prelle, A.; Fagiolari, G.; Rimoldi, M.; et al. Loss of ETHE1, a mitochondrial dioxygenase, causes fatal sulfide toxicity in ethylmalonic encephalopathy. Nat. Med. 2009, 15, 200-205.

33. Viscomi, C.; Burlina, A.B.; Dweikat, I.; Savoiardo, M.; Lamperti, C.; Hildebrandt, T.; Tiranti, V.; Zeviani, M. Combined treatment with oral metaronidazole and $\mathrm{N}$-acetylcysteine is effective in ethylmalonic encephalopathy. Nat. Med. 2010, 16, 869-871.

34. Shan, X.; Dunbrack, R.L.J.; Christopher, S.A.; Kruger, W.D. Mutation in the regulatory domain of cystathionine $\beta$-synthase can functionally suppress patient-derived mutations in cis. Hum. Mol. Genet. 2001, 10, 635-643.

35. Niu, W.-N.; Yadav, P.K.; Adame, J.; Banerjee, R. S-Glutathionylation enhances human cystathionine $\beta$-synthase activity under oxidative stress conditions. Antioxid. Redox Signal. 2014, in press.

36. Taoka, S.; Banerjee, R. Characterization of NO binding to human cystathionine $\beta$-synthase: Possible implications of the effects of $\mathrm{CO}$ and NO binding to the human enzyme. J. Inorg. Biochem. 2001, 87, 245-251.

37. Morikawa, T.; Kajimura, M.; Nakamura, T.; Hishiki, T.; Nakanishi, T.; Yukutake, Y.; Nagahata, Y.; Ishikawa, M.; Hattori, K.; Takenouchi, T.; et al. Hypoxic regulation of the cerebral microcirculation is mediated by a carbon monoxide-sensitive hydrogen sulfide pathway. Proc. Natl. Acad. Sci. USA. 2012, 109, 1293-1298.

38. Yang, G.; Wu, L.; Jiang, B.; Yang, W.; Qi, J.; Cao, K.; Meng, Q.; Mustafa, A.K.; Mu, W.; Zhang, S.; et al. $\mathrm{H}_{2} \mathrm{~S}$ as a physiologic vasorelaxant: Hypertension in mice with deletion of cystathionine $\gamma$-lyase. Science 2008, 322, 587-590. 
39. Mikami, Y.; Shibuya, N.; Ogasawara, Y.; Kimura, H. Hydrogen sulfide is produced by cystathionine $\gamma$-lyase at the steady-state low intracellular $\mathrm{Ca}^{2+}$ concentrations. Biochem. Biophys. Res. Commun. 2013, 431, 131-135.

40. Mikami, Y.; Shibuya, N.; Kimura, Y.; Nagahara, N.; Yamada, M.; Kimura, H. Hydrogen sulfide protects the retina from light-induced degeneration by the modulation of $\mathrm{Ca}^{2+}$ influx. J. Biol. Chem. 2011, 286, 39379-39386.

41. Nagahara, N.; Yoshii, T.; Abe, Y.; Matsumura, T. Thioredoxin-dependent enzymatic activation of mercaptopyruvate sulfurtransferase. An intersubunit disulfide bond serves as a redox switch for activation. J. Biol. Chem. 2007, 282, 1561-1569.

42. Nagai, Y.; Tsugane, M.; Oka, J.; Kimura, H. Hydrogen sulfide induces calcium waves in astrocytes. FASEB J. 2004, 18, 557-559.

43. Tsugane, M.; Nagai, Y.; Kimura, Y.; Oka, J.-I.; Kimura, H. Differentiated astrocytes acquire sensitivity to hydrogen sulfide that is diminished by the transformation into reactive astrocytes. Antioxid. Redox Signal. 2007, 9, 257-269.

44. Streng, T.; Axelsson, H.E.; Hedlund, P.; Andersson, D.A.; Jordt, S.E.; Bevan, S.; Andersson, K.E.; Hogestatt, E.D.; Zygmunt, P.M. Distribution and function of the hydrogen sulfide-sensitive TRPA1 ion channel in rat urinary bladder. Eur. Urol. 2008, 53, 391-399.

45. Nagy, P.; Winterbourn, C.C. Rapid reaction of hydrogen sulfide with the neutrophil oxidant hypochlorous acid to generate polysulfides. Chem. Res. Toxicol. 2010, 23, 1541-1543.

46. Kato, A.; Ogura, M.; Suda, M. Control mechanism in the rat liver enzyme system converting L-methionine to L-cystine. 3. Noncompetitive inhibition of cystathionine synthetase-serine dehydratase by elemental sulfur and competitive inhibition of cystathionine-homoserine dehydratase by L-cysteine and L-cystine. J. Biochem. 1966, 59, 40-48.

47. Branzoli, U.; Massey, V. Evidence for an active site persulfide residue in rabbit liver aldehyde oxidase. J. Biol. Chem. 1974, 249, 4346-4349.

48. Conner, J.; Russell, P.J. Elemental sulfur: A novel inhibitor of adenylate kinase. Biochem. Biophys. Res. Commun. 1983, 113, 348-352.

49. Mustafa, A.K.; Sikka, G.; Gazi, S.K.; Steppan, J.; Jung, S.M.; Bhunia, A.K.; Barodka, V.M.; Gazi, F.K.; Barrow, R.K.; Wang, R.; et al. Hydrogen sulfide as endothelium-derived hyperpolarizing factor sulfhydrates potassium channels. Circ. Res. 2011, 109, 1259-1268.

50. Sen, N.; Paul, B.D.; Gadalla, M.M.; Mustafa, A.K.; Sen, T.; Xu, R.; Kim, S.; Snyder, S.H. Hydroen sulfide-linked sulfhydration of NF-kB mediates its intiapoptotic actions. Mol. Cell 2012, $45,13-24$.

51. Krishnan, N.; Fu, C.; Pappin, D.J.; Tonks, N.K. $\mathrm{H}_{2} \mathrm{~S}$-induced sulfhydration of the phosphatase PTP1B and its role in the endoplasmic reticulum stress response. Sci. Signal. 2011, 4, ra86.

52. Vandiver, M.S.; Paul, B.D.; Xu, R.; Karuppagounder, S.; Rao, F.; Snowman, A.M.; Ko, H.S.; Lee, Y.I.I.; Dawson, V.L.; Dawson, T.M.; et al. Sulfhydration mediates neuroprotective actions of parkin. Nat. Commun. 2013, 4, doi:10.1038/ncomms2623.

53. Toa, B.B.; Liu, S.Y.; Zhang, C.C.; Fu, W.; Cai, W.J.; Wang, Y.; Shen, Q.; Wang, M.J.; Chen, Y.; Zhang, L.J.; et al. VEGFR2 functions as an $\mathrm{H}_{2} \mathrm{~S}$-targeting receptor protein kinase with its novel Cys1045-Cys1024 disulfide bond serving as a specific molecular switch for hydrogen sulfide actions in vascular endothelial cells. Antioxid. Redox Signal. 2013, 19, 448-464. 
54. Calvert, J.W.; Jha, S.; Gundewar, S.; Elrod, J.W.; Ramachandran, A.; Pattillo, C.B.; Kevil, C.G.; Lefer, D.J. Hydrogen sulfide mediates cardioprotection through Nrf2 signaling. Circ. Res. 2009, 105, 365-374.

55. Yang, G.; Zhao, K.; Ju, Y.; Mani, S.; Cao, Q.; Puukila, S.; Khaper, N.; Wu, L.; Wang, R. Hydrogen sulfide protects against cellular senescence via $S$-sulfhydration of Keap1 and activation of Nrf2. Antioxid. Redox Signal. 2013, 18, 1906-1919.

56. Stipanuk, M.H. Metabolism of sulfur-containing amino acids. Ann. Rev. Nutr. 1986, 6, 179-209.

57. Brigham, M.P.; Stein, W.H.; Moore, S. The concentrations of cysteine and cystine in human blood plasma. J. Clin. Investig. 1960, 39, 1633-1638.

58. Teague, B.; Asiedu, S.; Moore, P.K. The smooth muscle relaxant effect of hydrogen sulphide in vitro: Evidence for a physiological role to control intestinal contractility. Br. J. Pharmacol. 2002, 137, 139-145.

59. Kimura, H. Metabolic turnover of hydrogen sulfide. Front. Physiol. 2012, 3, 101.

60. Kabil, O.; Banerjee, R. Enzymology of $\mathrm{H}_{2} \mathrm{~S}$ biogenesis, decay and signaling. Antioxid. Redox Signal. 2014, 20, 770-782.

(C) 2014 by the authors; licensee MDPI, Basel, Switzerland. This article is an open access article distributed under the terms and conditions of the Creative Commons Attribution license (http://creativecommons.org/licenses/by/4.0/). 